\title{
Coupon Characteristics and Redemption Intentions: A Segment-Level Analysis
}

\author{
Venkatram Ramaswamy* \\ University of Michigan \\ Srini S. Srinivasan \\ Drexel University
}

\begin{abstract}
The authors investigate how different segments of consumers react to different coupon characteristics, such as face value and method of distribution. They utilize a latent segmentation approach to identify the underlying segments. The empirical analysis suggests that different segments of consumers place varying emphasis with regard to economic benefits, psychic benefits, effort costs, and substitution costs. A further examination of the derived segments with respect to consumer correlates such as psychological, attitudinal, behavioral, and demographic characteristics reveals that coupon-related consumer characteristics, rather than demographics, exhibit significant and meaningful differences across these segments. Implications of the segment-level analysis for evaluating coupon drops and managing promotional expenditures are also discussed. @1998 John Wiley \& Sons, Inc.
\end{abstract}

With 269 billion coupons distributed in 1996 in the United States, and approximately 5.3 billion coupons redeemed, for a total savings of $\$ 3.7$ billion (Brown, 1997), coupons continue to be among the most important promotional vehicles being used today. To improve the profitability of promotions, an in-depth understanding of the impact of promotions

*Both authors contributed equally to this article.

Psychology \& Marketing

(C) 1998 John Wiley \& Sons, Inc. 
is needed (Strang, 1976). To enhance our understanding of the impact of coupons on brand sales and coupon redemptions, researchers have used aggregate coupon redemption models (Leone \& Srinivasan, 1996; Reibstein \& Traver, 1982). Although such aggregate coupon redemption models are useful in understanding and predicting market-level redemption rates, not accounting for segment-level differences in response can potentially lead to biased estimates in these models (Chintagunta, Jain, \& Vilcassim, 1992). Also, aggregate models provide little insight into how sensitivities to coupon characteristics vary across the different segments in the market. To design effective coupon promotions managers need to understand how different segments of consumers respond to key coupon characteristics such as method of distribution, face value, and desirability of the brand being couponed.

Currently there are no empirical studies that identify and characterize these different segments of consumers. However, Dhar and Hoch (1996) speculate that the market could be thought of as consisting of three different segments: Segment 1 is composed of those price-sensitive shoppers who are expert coupon users, Segment 2 contains shoppers who are price and promotion insensitive, and Segment 3 consists of price-sensitive shoppers who are not adept at using coupons. Apart from such speculations, our theoretical understanding of how to segment the consumers in the market depending upon their sensitivity to coupon promotions is in its infancy. In this research a response-based segmentation approach is proposed and implemented. Such an approach has been gainfully utilized in other contexts such as brand choice behavior (Bucklin, Gupta, \& Han, 1995) and response to direct mail (DeSarbo \& Ramaswamy, 1994), to yield managerially actionable segments. In the present context, response-based segmentation enables us to

- Derive market segments that exhibit differences in the impact of coupon characteristics on the propensity to redeem coupons

- Estimate the size of the response-based segments and assign consumers to these segments

- Investigate how coupon characteristics affect redemption intentions in each segment

- Compute the expected market-level response for a coupon drop that takes into account the implicit segmentation in the marketplace.

In the next section, prior research on coupon redemption is discussed and a segment-level model of response to coupon characteristics is specified. A method to estimate the model using individual-level data on coupon characteristics and coupon redemption is discussed. Also, an application of this model with the use of data gathered in a field survey (wherein coupon characteristics are varied and consumers' intention to redeem them are elicited) is discussed. The responsebased segmentation approach reveals three different segments of con- 
sumers who differ significantly with respect to their sensitivities to coupon characteristics. Further, an examination of segment differences in consumer correlates such as psychological, attitudinal, behavioral, and demographic variables reveals that coupon-related variables, rather than demographic characteristics, exhibit significant and meaningful differences across these response-based segments. Insights from the derived segmentation scheme and their implication are discussed.

\section{COUPON CHARACTERISTICS AND REDEMPTION INTENTIONS}

\section{Role of Redemption Intentions}

In the past, researchers have investigated the impact of coupon characteristics on both redemption behavior (Reibstein \& Traver, 1982) and redemption intentions (Shoemaker \& Tibrewala, 1985). Investigating the impact of coupon characteristics on redemption rates is appealing, as managers can use the findings to predict redemption rates and the associated costs of the couponing program. However, there are some compelling reasons to model the impact of coupon characteristics on redemption intentions. First, in the case of store causal variables like temporary price reductions, consumers are exposed to the deal inside the store and need to act immediately to take advantage of the deal offer. But in the case of coupons (when a typical customer is sitting in his/her house, browsing through the Sunday newspaper and coming across coupons in the freestanding inserts ${ }^{1}$ ), the consumer need not redeem the coupons immediately. Instead, the consumer may form intentions to redeem coupons and these intentions might translate into actual behavior in a subsequent period of time. Second, as noted by Bagozzi, Baumgartner, and Yi (1992a), the actual coupon redemption behavior has been shown to be significantly affected by the intentions to redeem coupons. Third, Bagozzi, Baumgartner, and Yi (1992b) elaborate on how the use of coupons involves a series of deliberate steps (like scanning, evaluation, clipping, organizing, and redeeming) and that many internal and external forces might interfere with the performance of the targeted behavior. Actual coupon redemption requires some planning and implementation effort in addition to the formation of intentions. Several factors (such as end aisle displays of the couponed brand or loss of the clipped coupons) can moderate the translation of redemption intentions into actual redemption behavior. Given that coupon characteristics are postulated to affect redemption intentions (and subsequently behavior) our focus on redemption intention is consistent with our objective of identifying segments on the basis of sensitivities to coupon characteristics.

${ }^{1} \mathrm{NCH}$ (1993) reports that more than $80 \%$ of the coupons distributed in the U.S. are of this type. 


\section{Coupon Characteristics Affecting Redemption Intentions}

Based upon microeconomic theory, the redemption intention of a coupon is likely to be higher for a coupon offering higher utility (face value in our case) than for a coupon offering a lower utility. Research by Reibstein and Traver (1982) and Bawa and Shoemaker (1987b) also find that coupon face value is significantly related to redemption rate. The intention to redeem a coupon is a function of the net benefit to a consumer because of the use of a coupon. The net benefit to a consumer is a function of both the costs and benefits involved in the use of coupons. Ceteris paribus, the higher the effort required to redeem a coupon, the lower the net benefit to a consumer because of the use of coupons. Chakraborty and Cole (1991) found that coupon usage is influenced by the ease or difficulty with which consumers can redeem a coupon. Further, there are both theoretical reasons and indirect evidence to suggest that people who buy a brand regularly are more likely to redeem a coupon for the brand than those who buy the brand occasionally (Shoemaker \& Tibrewala, 1985). Bauer's (1960) theory of perceived risk suggests that there is little or no risk in using the coupon for a regular buyer of the brand. These consumers have relatively more experience with the brand, have trust in its performance, and know there is little chance of being disappointed. Hence, ceteris paribus, consumers who normally buy the couponed brand are likely to have a higher intention to redeem the coupons than consumers who occasionally buy the couponed brand.

In sum, some of the characteristics most likely to influence the intention to redeem a coupon are (a) the coupon face value, which determines the savings provided, (b) the type of coupon (e.g., freestanding insert coupons and mail-in coupons), which determines the effort required to collect and redeem it and (c) whether the coupon is for a preferred brand or for a brand the consumer occasionally purchases.

\section{EMPIRICAL ANALYSIS}

\section{Survey Instrument}

To empirically estimate the proposed model, consumers' intentions to redeem coupons for the detergent product category were collected. This category was chosen as most of the households tend to buy detergents and a number of detergent manufacturers regularly offer coupons in the market where the instrument was administered. An instrument was developed to measure consumers' intention to redeem different types of coupons in this category. Specifically, data on consumers' intention to redeem coupons of three different face values, three different methods of distribution (freestanding inserts, on-pack coupons and mail-in coupons) and for two types of brands (their fa- 
vorite brand and a brand they occasionally purchase) were collected. ${ }^{2}$ In addition, data on a number of other relevant background consumer characteristics (attitudinal and psychographic variables) were collected to compare the profile of consumers belonging to the different segments. Also, data on a number of demographic variables (like age, gender, and number of people living in the household) and data on general shopping behavior (like number of shopping trips made per month and number of coupons redeemed per month) were collected.

\section{Pretesting and Survey Administration}

A preliminary version of the instrument was administered to a group of graduate and undergraduate students. The questionnaire was modified from the feedback obtained from this group. Next the questionnaire was pretested with 37 shoppers drawn at random from three local grocery stores and further refined based upon their inputs. Five hundred questionnaires of this final version were distributed in two stores of a major grocery chain in a southwestern city. Customers waiting in the checkout line were randomly approached and were requested to participate in the survey. The customers were given a copy of the survey instrument, a prepaid return envelope, and a dollar bill as a token of appreciation. A total of 345 completed questionnaires were received, representing a satisfactory response rate of $69 \%$.

\section{Analytical Model}

Given these survey data, a latent segmentation approach is used to directly group consumers into segments based on their (unknown) sensitivities to coupon characteristics (DeSarbo, Ramaswamy \& Cohen, 1995). Each consumer is then assigned to the segment for which he/she has the highest probability of segment membership. These discrete response-based segments are then profiled in terms of various background consumer characteristics to gain more insight into the composition of the derived segments (DeSarbo \& Ramaswamy, 1994; Kamakura \& Mazzon, 1991). Analytical underpinnings of this latent segmentation approach are given in Appendix 1.

\section{EMPIRICAL RESULTS}

The AIC heuristic (Appendix 1) suggested that the market can be viewed as consisting of three segments of consumers. The parameter

\footnotetext{
${ }^{2}$ Intentions were measured on a dichotomous scale. For each of the different coupon profiles, consumers were asked if they would (or would not) redeem such a coupon during their subsequent shopping trip.
} 
estimates based on the model specification of Eq (2) (Appendix 1) are given in Table 1 for each of the three derived segments.

All the parameter estimates in Table 1 are statistically significant at the .05 level and exhibit high face validity. Ceteris paribus, coupons of higher face value are more attractive than coupons of lower face value, FSI coupons are more attractive, and mail-in coupons less attractive than on-pack coupons, and coupons for a favorite brand are more attractive than coupons for an occasionally purchased brand. There are, however, statistically significant variations in sensitivity to each of the coupon characteristics, as evinced by differences in parameter estimates across the three derived segments in Table 1.

\section{Characteristics of the Different Segments}

Bawa and Shoemaker (1987a) discuss a conceptual framework that can be used to understand the general redemption behavior of consumers. Put simply, their framework suggests that the net benefits of using a coupon have three components:

Net benefits of using a coupon $=$ economic and psychic benefits (substitution costs + effort costs).

As Blattberg and Neslin (1990, p. 288) note, "Economic and psychic benefits refer to face value savings and to non financial benefits such as the smart-shopper phenomenon. Substitution costs are the disutility the consumer incurs by possible purchasing brands he or she would not otherwise have bought. The substitution cost would be zero for the most preferred brand. Effort costs are due to the consumer searching for coupons and handling them."

Consider the net benefits of using a $\$ 1.05$ mail-in coupon versus a $75 \varnothing$ FSI coupon, both for a consumer's favorite brand. The economic benefit of the latter coupon is about the same as the former coupon after postage. FSI coupons are generally easier to redeem than mail-in

Table 1. Segment-Level Parameter Estimates from Coupon Redemption Model $^{\mathrm{a}}$

\begin{tabular}{lccr}
\hline & $\begin{array}{c}\text { Segment 1 } \\
(30.3 \%)\end{array}$ & $\begin{array}{c}\text { Segment 2 } \\
(33.4 \%)\end{array}$ & $\begin{array}{c}\text { Segment 3 } \\
(36.3 \%)\end{array}$ \\
\hline INTERCEPT & -1.78 & -3.04 & -3.38 \\
FCVAL (\$ face value) & 5.28 & 10.09 & 3.39 \\
MAIL (mail-in coupon) $^{\text {b }}$ & -3.79 & -17.32 & -4.20 \\
FSI $^{\mathrm{b}}$ (free-standing insert) & 0.17 & 0.16 & 0.22 \\
FAVBR (favorite brand) & 1.28 & 2.19 & 1.50 \\
\hline
\end{tabular}

Note: Segment size is in parentheses.

${ }^{a}$ All parameter estimates are significant at the 0.05 level.

${ }^{b}$ Base is on-pack coupons 
Table 2. Estimated Intentions to Redeem Different Types of Coupons by Segment

\begin{tabular}{lccc}
\hline Coupon Characteristics & $\begin{array}{c}\text { Coupon } \\
\text { Chasers } \\
\text { (Segment 1) }\end{array}$ & $\begin{array}{c}\text { Easy } \\
\text { Couponers } \\
\text { (Segment 2) }\end{array}$ & $\begin{array}{c}\text { Picky } \\
\text { Couponers } \\
\text { (Segment 3) }\end{array}$ \\
\hline Favorite brand & & & \\
$\quad$ \$1.05 mail-in coupon & 0.78 & 0.00 & 0.07 \\
75ф FSI coupon & 0.97 & 0.99 & 0.71 \\
\$1.50 mail-in coupon & 0.97 & 0.05 & 0.27 \\
Occasional brand & & & \\
75ф FSI coupon & 0.91 & 0.99 & 0.35 \\
\$1.50 mail-in coupon & 0.91 & 0.01 & 0.08 \\
\hline
\end{tabular}

coupons, which require more effort in terms of mailing in the proof of purchase to the manufacturer and awaiting a refund. Because the substitution cost is zero for both coupons, the 75ф FSI coupon should be more attractive unless the psychic benefits of using mail-in coupons outweigh the reduced effort costs of using FSI coupons. In other words, the difference in redemption intentions for a $75 \not$ FSI coupon versus a $\$ 1.05$ mail-in coupon should be greater than zero.

From Table 2, the expected redemption intentions for a $\$ 1.05$ mailin coupon for a consumer's favorite brand are $78 \%, 0 \%$, and $7 \%$ for the three segments. The expected redemption intentions for a $75 \phi$ FSI coupon offered for a consumer's favorite brand, are 97\%, 99\%, and $71 \%$, respectively. The incremental intentions for the $75 \varnothing$ FSI coupon (over the $\$ 1.05$ mail-in coupon) are thus $19 \%$, 99\%, and $64 \%$, respectively, for the three segments. Although all these values are significantly greater than zero, note that there is considerable variation across the segments. In particular, consumers in Segment 2 appear to place disproportionately more emphasis on effort costs. They are unwilling to expend the extra effort for redeeming mail-in coupons and increased waiting time for the refund, even though the monetary benefits may be higher for the mail-in coupons. Moreover, as long as the coupons require little effort to redeem, they do not mind redeeming them even for a competing brand (note that for an occasionally purchased brand with a $75 \phi$ FSI coupon, the expected redemption intention is $99 \%$ as opposed to $1 \%$ for a $\$ 1.50$ mail-in coupon). This segment appears to be more sensitive to the method of distribution than the nature of the brand being couponed. This segment is labeled as "easy couponers." About 33.4\% of consumers belong to this segment.

Consumers in Segment 1 appear to exhibit more emphasis on economic and psychic benefits. These consumers are relatively more willing to use coupons that require extra effort to redeem (like mail-in coupons). From Table 2, it can be observed that the propensity to redeem a $\$ 1.50$ mail-in coupon is very large for Segment 1, even for an occasionally pur- 
chased brand. Consumers in Segment 1 are more flexible in terms of redeeming coupons both for their favorite brand and for a brand they occasionally purchase, and are more likely to redeem coupons of lower face value. Hence, Segment 1 is labeled the "coupon chasers" segment, and this segment accounts for about $30.3 \%$ of all consumers.

Consumers belonging to Segment 3 appear to have higher substitution costs than consumers belonging to either of the other two segments. The increase in redemption for a $75 \varnothing$ FSI coupon for a favorite brand versus an occasional brand is $36 \%$ for Segment 3, as opposed to $6 \%$ and $0 \%$ for Segments 1 and 2 respectively. Similarly, the increase in redemption for a $\$ 1.50$ mail-in coupon for a favorite brand versus an occasional brand is $19 \%$ for Segment 3, as opposed to $6 \%$ and $4 \%$ for Segments 1 and 2, respectively. In general, consumers in Segment 3 are less willing to redeem FSI coupons for a brand they occasionally purchase than consumers belonging to Segment 2. A consumer in Segment 3 is about two times more likely to redeem a $75 \phi$ coupon if it is for a favorite brand than for a brand bought occasionally. Further, consumers in Segment 3 seem to have less aversion to mail-in coupons so long as the coupons are for a favorite brand. Recall that the expected redemption intention for a $\$ 1.05$ mail-in coupon for a favorite brand was $7 \%$ for Segment 3 . From Table 2, increasing the face value by $45 \varnothing$ increases this redemption intention to $27 \%$, but remains about the same at $8 \%$ for an occasionally purchased brand. Hence, relative to the other two segments, consumers in Segment 3 appear to be much more sensitive to the brand being couponed. For their favored brands, they appear to be less sensitive to the method of distribution than Segment 2 . This segment is labeled as "picky couponers." About $36.3 \%$ of consumers belong to this segment.

\section{Goodness of Fit and Validation of Derived Response-Based Segments}

Does the derived response-based segmentation scheme better explain the variability in consumers' intentions to redeem coupons? To answer this question the adjusted likelihood ratio index was calculated to assess the goodness of-fit for the segment-level model (Ben-Akiva \& Leman, 1985). ${ }^{3}$ This index adjusts for the increases in log likelihood due to an increase in number of estimated parameters, and is used in a fashion similar to adjusted $R^{2}$ in regression analysis. The value is 0.46 , which is considerably larger than the index value for an aggregate-level model of 0.28 . Hence, the segment-level model provides significantly more explanatory power than the aggregate-level model.

${ }^{3}$ The adjusted likelihood ration index is computed as (Ben-Akiva \& Lerman, 1985, p. 167):

$$
\bar{\rho}^{2}=1-\frac{(\text { model log likelihood }-k)}{\text { null log likelihood }} \text { where } k \text { is the number of estimated parameters. }
$$


To further validate the derived segmentation scheme, discrete segments were formed by assigning each respondent to the segment for which he/she had the highest posterior probability [computed with the use of Eq. (4) in Appendix 1]. The mean modal posterior probability was above 0.90 , indicating a lack of fuzziness in segment membership and justifying the formation of discrete segments. The sizes of the resulting discrete segments were almost identical to the estimated segment sizes.

\section{Profiling Consumers Belonging to the Different Segments}

To understand the differences in consumer correlates across the various segments, ANOVA (followed by Duncan's test where appropriate) was used. The consumer correlates used include psychological, attitudinal, behavioral, and demographic characteristics. An important psychological variable on which these segments are likely to differ is their coupon proneness. The overall coupon proneness of consumers was measured with the use of the eight-item coupon-proneness scale validated by Lichtenstein, Netemeyer, and Burton (1990). Data were also collected on the following constructs with the use of multiitem scales: (a) price consciousness (Wells \& Tigert, 1971), (b) value consciousness (Lichtenstein et al., 1990), (c) attitude toward the act of redeeming coupons (Shimp \& Kavas, 1984), (d) subjective norms (Shimp \& Kavas, 1984), and (e) perception of coupon availability in category (Bawa, Srinivasan, \& Srivastava, 1994). All the scales exhibit high internal consistency, attesting to their reliability. ${ }^{4}$

A comparison of the mean levels of the psychological, attitudinal, behavioral, and demographic variables among the three derived segments are given in Table 3. Pairwise comparisons employing Duncan's tests are indicated by asterisks. Considering the psychological variables. Table 3 shows that consumers belonging to the coupon chasers segment are the most coupon prone, consistent with their emphasis on economic/ psychic benefits and willingness to redeem coupons requiring more effort to redeem. The easy couponers are somewhat less coupon prone than the coupon chasers. The picky couponers are the least coupon prone, consistent with their selectivity in using coupons. They are also less price conscious, somewhat less value conscious, and have a lower perception of coupon availability.

The attitudinal variables in Table 3 are classified as coupon-related constructs and those constructs not related to coupons. Although consumers belonging to the three segments differ significantly on the coupon-related attitudinal variables, they do not differ significantly on the attitudinal constructs that are not related to coupons (such as attitude toward two for the price of one, price reductions, and free samples).

\footnotetext{
${ }^{4}$ The scale items used and their internal consistency estimates are given in Appendix 2.
} 


\section{Table 3. Mean Differences in Consumer Correlates Across Response-Based Segments}

\begin{tabular}{|c|c|c|c|c|c|}
\hline Consumer Characteristics & $\begin{array}{l}\text { Coupon Chasers } \\
\text { (Segment 1) }\end{array}$ & $\begin{array}{l}\text { Easy Couponers } \\
\quad(\text { Segment } 2)\end{array}$ & $\begin{array}{l}\text { Picky Couponers } \\
\text { (Segment 3) }\end{array}$ & $\begin{array}{c}\text { Differences } \\
\text { Significant } \\
\text { at } 0.05 \text { Level? }\end{array}$ & Duncan's Test ${ }^{\mathrm{a}}$ \\
\hline \multicolumn{6}{|l|}{ Psychological variables } \\
\hline Coupon proneness & 4.58 & 4.21 & 3.71 & Yes & $\mathrm{S} 1 \mathrm{~S} 2 \mathrm{~S} 3$ \\
\hline Price consciousness & 4.82 & 4.71 & 4.29 & Yes & $\underset{\substack{* * * * \\
\mathrm{~S} 1}}{\mathrm{~S} 2} \mathrm{~S} 3$ \\
\hline Value consciousness & 5.94 & 6.03 & 5.63 & Yes & $\underset{\substack{* * * * \\
\mathrm{~S}} \mathrm{~S} 1 \mathrm{~S} 3}{ }$ \\
\hline $\begin{array}{l}\text { Perception of coupon } \\
\text { availability in category }\end{array}$ & 5.75 & 5.59 & 5.29 & Yes & $\underset{\substack{* * * * *}}{\mathrm{~S} 1} \mathrm{~S} 2 \mathrm{~S} 3$ \\
\hline \multicolumn{6}{|l|}{ Attitudinal variables } \\
\hline \multicolumn{6}{|l|}{ Coupon related } \\
\hline $\begin{array}{l}\text { Attitude toward act } \\
\text { of redeeming coupons }\end{array}$ & 5.64 & 5.54 & 4.91 & Yes & $\begin{array}{lll}\mathrm{S} 1 & \mathrm{~S} 2 & \mathrm{~S} 3 \\
* * * * & \end{array}$ \\
\hline $\begin{array}{l}\text { Subjective norm toward act } \\
\text { of redeeming coupons }\end{array}$ & 5.30 & 5.33 & 4.80 & Yes & $\underset{* * * *}{\mathrm{~S} 2} \mathrm{~S} 1 \mathrm{~S} 3$ \\
\hline \multicolumn{6}{|l|}{ Not coupon related } \\
\hline $\begin{array}{l}\text { Attitude toward two for the } \\
\text { price of one }\end{array}$ & 5.99 & 5.77 & 5.62 & No & Not applicable \\
\hline
\end{tabular}


Attitude toward price

reductions marked on

product

Attitude toward free sample

5.30

5.21

No

Not applicable

Behavioral Variables

Coupon-related

Number of coupons redeemed

per month

Proportion of consumers

preferring a $\$ 1$ coupon over a

50 cents price reduction

Not Coupon-related

Usage volume for category

Number of shopping trips per

5.43

5.15

15.00

11.30

0.42

0.67

6.02

5.78

5.83

5.61

38.0

2.79

35.9
37.0

2.89

35.3
38.0

2.72

38.2
No

Yes

Yes

No

No

No

No

No
Not applicable

S1 S2 S3

S1 1 S2 S3

(simple t-test)

Not Applicable

Not Applicable

Not Applicable

Not Applicable

Not Applicable

aSegments connected by asterisks are not significantly different from each other at the 0.05 level. 
Note that picky couponers have a less positive attitude towards the act of redeeming coupons.

The behavioral variables in Table 3 are also classified as coupon-related constructs and those constructs not related to coupons. Although consumers belonging to the three segments differ significantly on the coupon-related variables, they do not differ significantly on the coupon-unrelated constructs (such as usage volume and number of monthly shopping trips). In particular, note that coupon chasers redeem the maximum number of coupons/month and picky couponers the least. Note also that the ordering of the proportion of consumers preferring a $\$ 1$ coupon over a $50 \notin$ price reduction within each segment parallels the ordering for the magnitude of segment-level coupon proneness, across the three segments.

Finally, demographic variables like age, family size, and number of hours worked per week do not show a significant difference across the three segments. Demographic variables have been shown to be rather poor predictors of coupon behavior (Mittal, 1994), and the data from this research corroborate such findings in prior research.

\section{Coupon Characteristics and Incremental Redemptions}

Bauer's (1960) theory of perceived risk suggests that there is less risk in using a coupon for a regularly purchased brand than for an occasionally purchased brand. Even at lower face values many regular buyers of the brand might intend to redeem the coupons. In case of regular buyers of the brand, an increase in face value may not attract many incremental consumers to redeem the coupons (Shoemaker \& Tibrewala, 1985). In the case of an occasionally purchased brand, at lower face values many consumers may not be willing to switch brands to redeem coupons. However, increasing the face value will make the occasionally purchased brand considerably more attractive. Hence, Shoemaker and Tibrewala (1985) argued that the incremental redemption from increasing face value is higher for an occasionally purchased brand compared to a favorite brand. Although this conjecture has been confirmed empirically by others (Klein, 1985), a key question in the present context is whether occasional brands exhibit higher incremental redemption intentions (relative to favorite brands) as face values are increased within each of the derived segments. With the use of the parameter estimates from Table 1, the segment-level incremental redemption intentions for increasing face values are shown in Table 4.

Consider an increase in face value from $40 \notin$ to $75 \phi$ for a FSI coupon. From Table 4, an occasional brand does have a larger incremental redemption than a favorite brand for consumers belonging to the coupon chasers and easy couponers segments. Among picky couponers, however, an occasional brand has lower incremental redemption than a fa- 
Table 4. Effect of Increasing Face Values on Incremental Redemption Intentions within Each Segment

\begin{tabular}{|c|c|c|c|}
\hline Increase in Face Values & $\begin{array}{c}\text { Coupon } \\
\text { Chasers } \\
\text { (Segment 1) }\end{array}$ & $\begin{array}{c}\text { Easy } \\
\text { Couponers } \\
\text { (Segment 2) }\end{array}$ & $\begin{array}{c}\text { Picky } \\
\text { Couponers } \\
\text { (Segment 3) }\end{array}$ \\
\hline \multicolumn{4}{|l|}{ Occasional brand } \\
\hline From $40 \phi$ to $75 \phi$, FSI coupon & 0.29 & 0.23 & 0.21 \\
\hline From $40 \varnothing$ to $75 \phi$, on-pack coupon & 0.32 & 0.26 & 0.18 \\
\hline From $\$ 1.00$ to $\$ 1.50$, mail-in coupon & 0.48 & 0.01 & 0.07 \\
\hline \multicolumn{4}{|l|}{ Favorite brand } \\
\hline From $40 \varnothing$ to $75 \phi$, FSI coupon & 0.11 & 0.03 & 0.29 \\
\hline From $40 \varnothing$ to $75 \varnothing$, on-pack coupon & 0.14 & 0.04 & 0.29 \\
\hline From $\$ 1.00$ to $\$ 1.50$, mail-in coupon & 0.24 & 0.05 & 0.21 \\
\hline
\end{tabular}

vorite brand. This same pattern is also observed in increasing the face value for on-pack coupons from $40 \notin$ to $75 \phi$. Picky couponers incur higher substitution costs and are reluctant to try an occasional brand even at higher face values. Hence, an occasional brand is less likely to gain more redeemers among picky couponers even at higher face values. This appears to hold for both FSI and on-pack coupons.

In the case of mail-in coupons, the incremental redemptions reveal additional differences across the segments. Among coupon chasers, the incremental redemption for an occasional brand is about twice as much as that of a favorite brand. Easy couponers exhibit low incremental redemption rates, regardless of the brand being couponed, which can be explained by their general aversion to redeeming mail-in coupons. Picky couponers again exhibit a lower incremental redemption rate for an occasional brand mail-in coupon relative to a mail-in coupon for a favorite brand, as well as relative to FSI and on-pack coupons.

In sum, the conjecture of Shoemaker and Tibrewala (1985) appears to hold regardless of the method of distribution in the coupon chasers segment. In contrast, the conjecture appears to be reversed in the picky couponers segment, regardless of method of distribution. In the easy couponers segment, their conjecture holds for FSI and on-pack coupons, but not for mail-in coupons. Hence, the ability to achieve incremental redemptions with a coupon appears to depend upon the extent of consumer heterogeneity in the market with respect to loyalty toward the couponed brand (substitution costs), responsiveness to face values (economic benefits), and disposition toward the type of coupon vehicle (effort costs and psychic benefits).

\section{Implications for Evaluating Coupon Drops}

Once couponing has been selected as a promotional vehicle, managers are interested in understanding how the market is going to respond to 
different coupon characteristics. Some of the concerns of brand managers are: How does face value affect coupon redemptions? How does the method of distribution affect coupon redemptions? In the past, researchers have attempted to answer such questions by assuming that the market as a whole behaves homogeneously (Reibstein \& Traver, 1982). This research has proposed an extension to the typical approach of investigating coupon redemption rates at the market level. As not all consumers in the market are likely to behave similarly, a responsebased segmentation scheme was used to identify different segments of consumers who are relatively more homogeneous in their response to coupon characteristics.

The proposed segment-level model can be used to arrive at an estimate of market-level redemption for coupons issued by any specific brand. Consider a category where two brands, A and B, dominate the market. Suppose that these brands have market shares of $75 \%$ and $25 \%$, respectively. When Brand A drops a coupon, those consumers who are regular buyers of the brand do not incur any switching costs when they redeem the coupon. But consumers who normally buy Brand B will incur switching costs to redeem the coupon for brand A. Similarly, when Brand B drops a coupon, consumers who normally buy Brand B do not incur any switching cost to redeem the coupons, whereas consumers who normally buy Brand A incur a switching cost to redeem the coupon. As Brand A commands a higher market share than Brand $\mathrm{B}$, the market-level intention to redeem coupons should be higher for Brand A than for Brand B.

With the use of expression (5) (in Appendix 1), the market-level intentions to redeem four different types of coupons (40ф FSI, $75 \varnothing$ FSI, $75 \varnothing$ mail-in, and $\$ 1.00$ mail-in coupons) can be calculated. The Calculated redemption intentions for brands $\mathrm{A}$ and $\mathrm{B}$ are

\begin{tabular}{lcc}
\hline Coupon Characteristics & Brand A & Brand B \\
\hline 40ф, FSI coupon & 0.68 & 0.55 \\
75ф, FSI coupon & 0.84 & 0.77 \\
75ф, Mail-in coupon & 0.12 & 0.07 \\
$\$ 1.00$, Mail-in coupon & 0.21 & 0.17 \\
\hline
\end{tabular}

Consumers who normally buy a brand do not incur any switching cost to redeem a coupon for their favorite brand. Hence the market-level redemption intention is indeed larger for brand $\mathrm{A}$ (higher market share brand) than for brand B (lower market share brand), in each of the four cases.

In sum, recognizing the heterogeneity in the market enhances the usefulness of market-level redemption estimates. Further, by capturing market heterogeneity via the derived response-based segments, one can obtain insights into how different types of coupons affect market- 
level redemptions. Manufacturers of consumer goods can replicate this research study by eliciting redemption intentions focusing on their specific brands. This will give them unique insights on the sensitivities of the different segments to coupon face value and method of distribution. Neslin and Clarke (1987) note that the distribution vehicle of the coupons is expected to influence the profile of consumers who redeem coupons. For example, as the results indicate, using mail-in coupons will not appeal to the easy couponers segment. Neslin and Clarke discuss the importance of understanding the redeemer profile of the consumers. To the extent that the coupon use profile among a brand's redeemers is skewed more toward new triers and rare or occasional purchasers, the coupon is inducing more incremental sales. To investigate the redeemer profile of consumers belonging to these three segments, brand managers can collect information on the prior likelihood of purchasing the focal brand by each of these three segments. With the use of this information, brand managers are in a better position to understand how the redeemer profiles of the three segments of consumers differ depending upon the method of coupon distribution.

\section{CONCLUSION}

Marketing is the biggest discretionary spending area in most companies, and CEOs are demanding a higher level of accountability from marketing than ever before (Sheth \& Sisodia, 1995). Hence, marketing managers are faced with the increasing burden of optimally utilizing their scarce promotional dollars. Instead of conducting a market-level analysis of redemption intentions, a segment-level analysis is proposed. Such a segment-level analysis gives potentially better insights into the profitability of couponing, as the incremental redemptions due to couponing could be different for the various segments in the market. The insights from such an analysis can be used not only to decide the face value of the coupon to be dropped, but also its method of distribution.

The latent segmentation analysis reveals that there are three distinct segments of consumers (coupon chasers, easy couponers, and picky couponers), who exhibit distinct differences in response to coupon characteristics such as face value and method of distribution. Knowledge of their differential responsiveness to coupon characteristics can be utilized to have consumers "self-select" themselves (Moorthy, 1984). For example, the method of distribution of the coupons significantly affects the way the three segments respond to coupon drops. Different types of coupons can be used to access one or more segments. The use of mail-in coupons is unlikely to attract consumers belonging to the easy couponers segment. However, depending upon the extent to which the couponed brand is preferred among the consumers belonging to the 
picky couponers segment, the mail-in coupon might attract consumers belonging to this segment consistent with the preference of the couponed brand. Such a segment-level approach to evaluating coupon promotions can help managers allocate their promotional expenditures more effectively.

As with any empirical research effort, this study is not without limitations. In an effort to appear rational, some respondents may have overstated their true level of intentions to redeem coupons, whereas others may have understated their intentions. As mentioned, the focus of this study is on the relative influence of coupon characteristics. Nevertheless, to the extent that respondents in one segment overstated/ understated their intentions to a different degree than respondents in another segment, the conclusions may have been affected. The results from the validation of the derived segmentation scheme, however, suggest that this effect is minimal. Another limitation of this study is that only the consumer's favorite brand and occasionally purchased brand are examined. The proposed framework can be extended to incorporate further variation in the desirability of the couponed brand.

With the availability of scanner panel data, the study could be extended to model coupon redemptions. The proposed model of coupon redemption can be estimated with individual-level redemptions data from several coupon drops. Future researchers might also investigate the relationship between redemption intentions and actual redemption behavior and the extent to which this relationship is stable across different segments. Also, future researchers should investigate a number of other behavioral and psychographical variables to capture the profile of consumers belonging to the different segments. For example, heavy users of coupons have been hypothesized to engage in more outof-store decision making (Bettman, 1979; Henderson, 1988). As consumers belonging to coupon chasers segment are the most likely to redeem coupons, it will be of interest to examine potential differences in in-store behavior (such as number of brands examined in a category, time spent examining brands, and information gathered about price) for consumers belonging to different segments.

\section{APPENDIX 1}

\section{Response-Based Latent Segmentation Approach}

Let $p_{j}$ denote the intention of a consumer to redeem coupon $j$. A logit model that links the intention to redeem coupons and coupon characteristics can be specified as follows:

$$
p_{j}=\frac{\exp \left(\alpha+\beta F C V A L_{j}+\gamma_{1} F S I_{j}+\gamma_{2} M A I L_{j}+\delta F A V B R_{j}\right)}{1+\exp \left(\alpha+\beta F C V A L_{j}+\gamma_{1} F S I_{j}+\gamma_{2} M A I L_{j}+\delta F A V B R_{j}\right)},
$$


where

$F C V A L_{j}=$ face value of coupon $j$ in dollars

$F S I_{j}=1$ if method of distribution of coupon $j$ is a free-standing insert; 0 otherwise

$M A I L_{j}=1$ if method of distribution of coupon $j$ is a mail-in coupon; 0 otherwise

$\left(F S I_{j}=0\right.$ and $M A I L_{j}=0$ denote on on-pack method of distribution)

$F A V B R_{j}=1$ if coupon $j$ is for the consumer's favorite brand; 0 otherwise

The response-based segmentation approach rests on the premise that the market consists of a number of finite segments $S$, each characterized by a specific vector of parameters capturing the segmentlevel sensitivity to coupon characteristics. Hence, for all consumers belonging to a particular segment $s$, the coupon redemption model in expression (1) now becomes

$p_{s j}=\frac{\exp \left(\alpha_{s}+\beta_{s} F C V A L_{j}+\gamma_{1 s} F S I_{j}+\gamma_{2 s} M A I L_{j}+\delta_{s} F A V B R_{j}\right)}{1+\exp \left(\alpha_{s}+\beta_{s} F C V A L_{j}+\gamma_{1 s} F S I_{j}+\gamma_{2 s} M A I L_{j}+\delta_{s} F A V B R_{j}\right)}$,

where $p_{s j}$ is the likelihood of redeeming coupon $j$ for a consumer belonging to segment $s$, and the response parameters now reflect the segment-level response to coupon characteristics. If the size of each segment is denoted as $w_{s}\left(0 \leq w_{s} \leq 1\right)$, then the likelihood of consumer $i$ redeeming coupon $j$ is given by

$$
p_{i j}=\sum_{s=1}^{s} w_{s} p_{s j},
$$

where $w_{s}$ can be interpreted as the prior (unknown) probability of consumer $i$ belonging to segment $s$. It is important to note that the parameters of the model for each segment, like those of any nonlinear regression model, are not necessarily the marginal effects. For segment $s$, the expected marginal effect, or increase in redemption for a change in characteristic $k$ for coupon $j$, can be shown to be $\hat{\theta}_{s k}^{*} \hat{p}_{s j}^{*}$ $\left(1-\hat{p}_{s j}\right)$, where $\hat{\theta}_{s k}$ is the estimated value of the segment-specific parameter for characteristic $k$, and $\hat{p}_{s j}$ is the estimated segment-level redemption intention for coupon $j$.

Given data for a sample of consumers entailing specific coupon characteristics and intentions to redeem coupons $\left(y_{i j}=1\right.$ if consumer $i$ intends to redeem coupon $j$, or 0 otherwise), maximum-likelihood logit mixture estimation (DeSarbo et al., 1995) can be utilized to estimate the segment sizes $w_{s}$, and the segment-specific response parameters $\left\{\alpha_{s}, \beta_{s}, \gamma_{1 s}, \gamma_{2 s}\right.$, and $\delta_{s}$ ], for a specified number of segments $S$. Because the value of $S$ is typically unknown, the procedure can be repeated by 
varying the number of segments and using an information heuristic such as the AIC (Akaike Information Criterion) to choose an appropriate solution that provides substantial improvement in fit with only a few additional parameters. Upon estimation, the appropriate number of segments, the sizes of each segment, and segment-specific response parameters are obtained. The parameter estimates can be used to

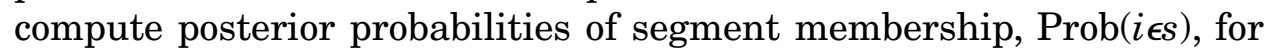
each consumer $i$ belonging to segment $s$ :

$$
\operatorname{prob}(i \epsilon s)=\frac{\hat{w}_{s} \prod_{j=1}^{J} \hat{p}_{s j}^{y_{i j}}}{\sum_{s=1}^{S} \hat{w}_{s} \prod_{j=1}^{J} \hat{p}_{s j}^{y_{i j}}}
$$

Each consumer can then be assigned to the segment for which he or she has the highest probability of segment membership. These discrete response-based segments can then be profiled in terms of various background consumer characteristics to gain more insight into the composition of the derived segments.

The proposed model can be utilized to arrive at an estimate of market-level redemption for a coupon issued by a specific brand. If brand $j$ drops a FSI coupon of $\$ x$, then the likelihood of a consumer $i$ redeeming this coupon can be calculated when the use of expression (3), contingent upon the desirability of brand $j$ by segment $s$. If one uses the market share for brand $j$ as a surrogate for the desirability of brand $j$ by consumer $i$, the segment-level redemption of a coupon for brand $j$ can be calculated as

$$
\begin{aligned}
R_{s j} & =M_{j}^{*}\left(\hat{p}_{s j} \mid \$ x, \text { FSI,FAVBR }=1\right) \\
& +\left(1-M_{j}\right) *\left(\hat{p}_{s j} \mid \$ x, \text { FSI,FAVBR }=0\right),
\end{aligned}
$$

where,

$M_{j}=$ market share of brand $j$,

$p_{s j}=$ likelihood of a consumer in segment $s$ redeeming the coupon for brand $j$.

The market-level redemption for brand $j$ can then be computed as a weighted average, $\Sigma_{s} w_{s} R_{s j}$, of the segment-level redemption estimates.

\section{APPENDIX 2}

The scale items used in the field survey are given below. All items are 7-point Likert-type scales ranging from "strongly agree" to "strongly 
disagree," unless otherwise stated. All scale items were coded/recoded so that higher scores reflect higher levels of the measured construct.

Coupon Proneness (Lichtenstein et al., 1990)

- Redeeming coupons makes me feel good.

- I enjoy clipping coupons out of the newspaper.

- When I use coupons, I feel that I am getting a good deal.

- I enjoy using coupons, regardless of the amount I save by doing so.

- I have favorite brands, but most of the time I buy the brand I have a coupon for.

- I am more likely to buy brands for which I have a coupon.

- Coupons have caused me to buy products I normally would not buy.

- Beyond the money I save, redeeming coupons give me a sense of joy.

Value Consciousness (Lichtenstein et al., 1990)

- I am very concerned about low prices, but I am equally concerned about product quality.

- When grocery shopping, I compare the prices of different brands to be sure I get the best value for the money.

- When purchasing a product, I always try to maximize the quality I get for the money I spend.

- When I buy products, I like to be sure that I am getting my money's worthy.

- I generally shop around for lower prices on products, but they still must meet certain quality requirements before I will buy them.

- When I shop, I usually compare the price per ounce information for brands I normally buy.

- I always check prices at the grocery store to be sure I get the best value for the money I spend.

Price Consciousness (Wells \& Tigert, 1971)

- I shop a lot for specials.

- I find myself checking the prices in the grocery store even for small items.

- I usually watch the advertisements for announcements of sales.

- A person can save a lot of money by shopping around for bargains. 
Attitude toward the Act of Redeeming Coupons (Shimp \& Kavas, 1984)

Respondents were asked to express their attitude toward the act of using coupons on semantic-differential scales. Scale anchors were foolish/wise, useful/useless, waste of time/wise use of time, valuable/worthless and $\mathrm{good} / \mathrm{bad}$.

\section{Subjective Norm (Shimp \& Kavas, 1984)}

The measure involved summation of five 7-point bipolar scales in response to the question: "Most people who are important to me probably consider my use of coupons to be ..." The five items used were foolish/wise, useful/useless, waste of time/wise use of time, valuable/worthless, and $\mathrm{good} / \mathrm{bad}$.

Internal Consistency (Cronbach's alpha) of Scales Used

\begin{tabular}{lcc}
\hline Consumer Characteristic & Number of Items & Cronbach's $\alpha$ \\
\hline $\begin{array}{l}\text { Coupon proneness } \\
\quad(\text { Lichtenstein, et al., 1990) }\end{array}$ & 8 & 0.84 \\
$\begin{array}{l}\text { Attitude toward the act of redeeming coupons } \\
\quad(\text { Shimp \& Kavas, 1984) }\end{array}$ & 5 & 0.82 \\
$\begin{array}{l}\text { Subjective norms } \\
\quad(\text { Shimp \& Kavas, 1984) }\end{array}$ & 5 & 0.88 \\
$\begin{array}{l}\text { Value consciousness } \\
\quad(\text { Lichtenstein, et al., 1990) }\end{array}$ & 7 & 0.78 \\
$\begin{array}{l}\text { Price consciousness } \\
\quad(\text { Wells \& Tigert, 1971) }\end{array}$ & 4 & 0.72 \\
\hline
\end{tabular}

\section{REFERENCES}

Bagozzi, R. P., Baumgartner, H., \& Yi, Y (1992a). State versus action orientation and the theory of reasoned action: An application to coupon usage. Journal of Consumer Research, 18, 24-27.

Bagozzi, R. P., Baumgartner, H., \& Yi, Y. (1992b). Appraisal process in the enactment of intentions to use coupons. Psychology and Marketing, 9, 469-486.

Bauer, R. A. (1960). Consumer behavior as risk taking. In Robert S. Hancock (Ed.), Proceedings of the 43rd national conference of the American Marketing Association (pp. 38-42). Chicago: American Marketing Association.

Bawa, K., \& Shoemaker, R. W. (1987a). The coupon-prone consumer: Some findings based on purchase behavior across product classes. Journal of Marketing, 51, 99-110.

Bawa, K., \& Shoemaker, R. W. (1987b). The effects of a direct mail coupon on brand choice behavior. Journal of Marketing Research, 24, 370-376.

Bawa, K., Srinivasan, S. S., \& Srivastava, R. K. (1994). Coupon proneness and coupon attractiveness: An item response theoretic approach to modeling coupon redemptions. Working paper, Drexel University, Philadelphia. 
Ben-Akiva, M. \& Lerman, S. R. (1985). Discrete choice analysis. Cambridge, MA: MIT Press.

Bettman, J. R. (1979). An information processing theory of consumer choice. Reading, MA: Addison-Wesley.

Blattberg, R. C., \& Neslin, S. A. (1990). Sales promotion: Concepts, methods and strategies. Englewood Cliffs, NJ: Prentice-Hall.

Brown, C. (1997). Coupon effectiveness improved in 1996. NCH Promotional Services News Release, January 22.

Bucklin, R. E., Gupta, S., \& Han, S. (1995). A brand's eye view of response segmentation in consumer brand choice behavior. Journal of Marketing Research, 32, 66-74.

Chakraborty, G., \& Cole, C. (1991). Coupon characteristics and brand choice. Psychology and Marketing, 8, 145-159.

Chintagunta, P. K., Jain, D. C., \& Vilcassim, N. J. (1992). Investigating heterogeneity in brand preferences in logit models for panel data. Journal of Marketing Research, 28, 417-428.

DeSarbo, W. S., \& Ramaswamy, V. (1994). CRISP: Customer response based iterative segmentation procedures for response modeling in direct marketing. Journal of Direct Marketing, 8, 7-20.

DeSarbo, W. S., Ramaswamy, V., \& Cohen, S. (1995). Market segmentation with choice-based conjoint analysis. Marketing Letters, 6, 137-147.

Dhar, S. K., \& Hoch, S. J. (1996). Price discrimination using in-store merchandising. Journal of Marketing, 60, 17-30.

Henderson, C. M. (1988). The interaction of coupons with price and store promotions. In Michael J. Houston (Eds.), Advances in consumer research (Vol. 15, pp. 364-371). Provo, UT: Association for Consumer Research.

Kamakura, W. A., \& Mazzon, J. A. (1991). Value segmentation: A model for the measurement of values and value systems. Journal of Consumer Research, $18,208-218$.

Klein, R. L. (1985). How to use research to make better sales promotion marketing decisions. In Stanley Ulanoff (Eds.), Handbook of sales promotion (pp. 457-466). New York: McGraw-Hill.

Leone, R. P., \& Srinivasan, S. S. (1996). Coupon face value: Its impact on coupon redemption, brand sales, and brand profitability. Journal of Retailing, 72, 273-290.

Lichtenstein, D. R., Netemeyer, R. G., \& Burton, S. (1990). Distinguishing coupon proneness from value consciousness: An acquisition-transaction utility theory perspective. Journal of Marketing, 54, 54-67.

Mittal, B. (1994). An integrated framework for relating diverse consumer characteristics to supermarket coupon redemption. Journal of Marketing Research, 31, 533-544.

Moorthy, K. S. (1984). Market segmentation, self-selection, and product line design. Marketing Science, 3, 288-305.

$\mathrm{NCH}$ (1993). Worldwide coupon distribution trends. Chicago: Author.

Neslin, S. A., \& Clarke, D. G. (1987). Relating the brand use profile of coupon redeemers to brand and coupon characteristics. Journal of Advertising Research, 27, 23-32.

Reibstein, D. J., \& Traver, P. A. (1982). Factors affecting coupon redemption rates. Journal of Marketing, 46, 102-113.

Sheth, J. N., \& Sisodia, R. K. (1995). Improving Marketing Productivity. In 
Marketing encyclopedia, issues \& trends shaping the future. Chicago: American Marketing Association.

Shimp, T. A., \& Kavas, A. (1984). The theory of reasoned action applied to coupon usage. Journal of Consumer Research, 11, 795-809.

Shoemaker, R. W., \& Tibrewala, V. (1985). Relating coupon redemption rates to past purchasing of the brand. Journal of Advertising Research, 25, 40-47.

Strang, R. A. (1976). Sales promotion-fast growth, faulty management. Harvard Business Review, 115-124.

Wells, W. D., \& Tigert, D. (1971). Activities, interests and opinions. Journal of Advertising Research, 11, 27-35.

Funding for this research was provided by the University of Texas at Austin.

Correspondence regarding this article should be sent to: S. S. Srinivasan, Department of Marketing, College of Business and Administration, Drexel University, 32nd and Chestnut Streets, Philadelphia, PA 19104 (swminats @duvm.ocs.drexel.edu). 